\title{
O Ensino de Matemática nas Páginas da Revista Educação em Mato Grosso (1978-1986)
}

\author{
Mathematics Teaching on the Pages of the Education Journal in Mato Grosso (1978-1986)
}

\author{
Juliana Stascovian ${ }^{\mathrm{a}}$, Laura Isabel Marques Vasconcelos de Almeida*a
}

aUniversidade de Cuiabá, Programa de Pós-Graduação Stricto Sensu em Ensino. MT, Brasil.

*E-mail: lauraisabelvasc@hotmail.com.

\begin{abstract}
Resumo
O artigo é resultado da pesquisa de Mestrado intitulada Revista Educação em Mato Grosso: orientações pedagógicas sobre a disciplina de Matemática para o Ensino Primário nas escolas públicas mato-grossenses (1978-1986). O estudo retrata o ensino de Matemática sob o olhar da Revista Educação em Mato Grosso - REMT elaborada e socializada pela Secretaria de Estado de Educação de Mato Grosso - SEDUC/MT com o objetivo de formar os professores primários e aproximar o órgão governamental dos profissionais da educação. Ancorado na abordagem metodológica histórico-cultural, a pesquisa fundamentou-se em autores renomados que discutem com propriedade os conceitos de apropriação, cultura escolar, imprensa pedagógica e formação de professores contribuindo para a historiografia da educação matemática. Os dados revelam que além de vasta informação, a Revista oferecia sugestões de trabalho e partilha de experiências bem-sucedidas realizadas pelas unidades escolares, contribuindo com o processo de ensino aprendizagem nas escolas públicas primárias mato-grossenses.
\end{abstract}

Palavras-chave: Ensino de Matemática. Impresso Pedagógico. Formação de Professores.

\begin{abstract}
The article is the result of a Master's research entitled Revista Educação em Mato Grosso: pedagogical guidelines on the subject of Mathematics for Primary Education in public schools in Mato Grosso (1978-1986). The study portrays the Mathematics Teaching from the perspective of "Revista Educação em Mato Grosso (REMT)," which was thought, elaborated and socialized by the Mato Grosso State Secretariat of Education (SEDUC / MT) with the objective of training primary teachers and bring the government agency closer to education professionals. Anchored in the historical-cultural methodological approach, the research was based on renowned authors who discuss appropriately the concepts of appropriation, school culture, pedagogical press and teacher education, contributing to the mathematics education historiography. The data reveal that in addition to extensive information, the magazine offered work suggestions and shared successful experiences carried out by the school units, contributing to the teaching-learning process in public primary schools in Mato Grosso.
\end{abstract}

Keywords: Mathematics Teaching. Pedagogical Form. Teacher Training.

\section{Introdução}

A "Revista Educação em Mato Grosso", objeto de estudo desta pesquisa foi publicada pela Secretaria de Estado de Educação de Cultura/MT (SEDUC/MT) no período de 1976 a 1986 e ao longo do período, constituiu-se como elemento essencial para a formação profissional e o desempenho pedagógico dos professores primários nas escolas públicas mato-grossenses. Possivelmente seu conteúdo contribuiu e certamente influenciou no processo de ensino e aprendizagem na disciplina de Matemática e consequentemente no trabalho do professor em sala de aula.

Os 35 exemplares apontam vestígios da prática pedagógica de outros tempos e nos permite aproximar de um contexto educativo diferente dos dias atuais, considerando o tempo histórico e remoto de mobilidade que circulou nas escolas públicas primárias com a tarefa de disseminar as ideias pedagógicas vigentes da época. Partindo desses princípios, que nos propomos a pesquisar como esses impressos pedagógicos foram planejados e qual era o papel da Revista nas unidades escolares de Mato Grosso.

\section{Material e Métodos}

\subsection{Aspectos metodológicos}

A abordagem metodológica da pesquisa fundamenta-se na perspectiva histórico-cultural e utiliza-se dos conceitos de apropriação (CHARTIER, 1990), disciplina escolar (CHERVEL, 1990), cultura escolar (JULIA, 2001) e imprensa pedagógica (NÓVOA, 1992) tendo como elementos essenciais as fontes (impressos pedagógicos, documentos escolares e a legislação vigente) para compreendermos o ensino dessa disciplina em outros tempos.

Nesta perspectiva, torna-se essencial socializar as pesquisas que tem contribuído com as produções acadêmicas no Brasil e também inventariar os materiais produzidos, na tentativa de suprir lacunas e posteriormente contribuir com a produção científica no que existe de novo.

No ano de 2015, foi realizado em Curitiba o XII Seminário Temático pelo GHEMAT denominado "Saberes elementares matemáticos do ensino primário (1890 - 1970): o que dizem as Revistas Pedagógicas?" que enfatizaram a relevância 
dos impressos e foram abordadas várias publicações de distintos estados, bem como algumas de circulação nacional, porém a Revista Educação em Mato Grosso neste período, não apresentava nenhum estudo com destaque para os conhecimentos matemáticos.

Neste sentido, considerando que a historiografia relacionada a disciplina de Matemática na abordagem histórica ainda é escassa no estado de Mato Grosso, a Revista Educação em Mato Grosso oferece um material rico, direcionado as escolas públicas primárias da rede estadual, torna-se necessário a abordagem de tópicos alusivos ao ensino de Matemática nos primeiros anos de escolarização.

Com a intenção de responder o problema de pesquisa, "Em que medida a Revista Educação em Mato Grosso se configurava como um instrumento orientador do trabalho pedagógico do professor para o ensino de Matemática nas escolas públicas estaduais de Mato Grosso?" O trabalho foi organizado objetivando compreender como os impressos pedagógicos disseminados pela Secretaria de Estado de Educação de Cultura/MT (SEDUC) se configuravam como instrumento pedagógico para as escolas públicas primárias de Mato Grosso no período de 1978 a 1986.

Nos seus estudos, Julia (2001), afirma que conhecer a trajetória de uma disciplina na perspectiva da história cultural, não é uma tarefa fácil. Segundo o autor requer um olhar minucioso para as finalidades do ensino, dos conteúdos a serem ensinados e suas formas de apropriação pelos professores e alunos. Ao buscar o sentido para o conceito de apropriação enquanto história cultural, o autor recorre a Chartier (1990), focando nos sujeitos produtores e também nos receptores da cultura.

Julia (2001) ainda sugere que ao olhar os registros e os documentos escolares, o pesquisador deve buscar compreender as transformações ocorridas na disciplina escolar. É um gesto que permite interrogar acerca da longa tradição e do consenso que pairam sobre as finalidades do ensino e sobre a suposta imutabilidade da cultura escolar.

\section{Resultados e Discussão}

\subsection{Revista Educação em Mato Grosso e o ensino de Matemática}

As trinta e cinco edições da Revista Educação em Mato Grosso, com a tarefa de orientar e formar os profissionais da época circulou pelas escolas públicas mato-grossenses, disseminando a cultura local e os mais variados assuntos e conteúdo a serem ministrados nas diferentes áreas de conhecimento, em específico, destacamos a disciplina de Matemática.

O impresso trazia muitas informações inerentes ao processo educativo da época, em cinco exemplares, o livro didático é enaltecido pela importância como coadjuvante do trabalho docente, a conscientização de que é um material que deve ser bem explorado e que o aluno deve aprender a zelar, além disso, traz toda informação de como selecionar a melhor obra para cada realidade escolar. Os autores recomendam os cuidados devido a seu papel primordial em todas as disciplinas, com destaque para a disciplina de Matemática que traz os seguintes itens para julgamento na escolha do livro dentre os disponíveis com pontuação para cada quesito:

1. Há preocupação com o atendimento dos objetivos específicos e sociais da Matemática - 2 pontos.

2. Apresenta exercícios variados na introdução, desenvolvimento e fixação de conteúdos - 2 pontos.

3. Apresenta atividades para serem desenvolvidas utilizando materiais concretos -2 pontos.

4. Sugere problemas que apresentam estruturas matemáticas formadas e focalizam situações significativas para o educando -3 pontos.

5. Apresenta compreensão do vocabulário técnico usado para expressar as relações numéricas e os princípios quantitativos -3 pontos.

6. Há preocupação no desenvolvimento da habilidade de descobrir, elaborar, enunciar e usar fórmulas e princípios surgidos de relações numéricas -3 pontos (MATO GROSSO, 1981).

A pontuação máxima era 15 pontos, também havia uma tabela específica para avaliação do manual do mestre, este foi elaborado de forma geral, sem estabelecer correlação com qualquer disciplina, contemplava uma relação de critérios para a escolha, observando apenas como o conteúdo era distribuído e as características físicas (dimensões, aparência, qualidade).

A Matemática tem pontuação maior nos itens estruturais da disciplina, realçando a atenção para o modelo das atividades, cuidados com a linguagem matemática correta e adequada para a faixa etária que o livro se destinava, sobressaindo também à intenção de não passar o conteúdo como pronto ou acabado, mas instigando o estudante para fazer suas próprias correções e verificações, traçar estratégias e sentir prazer nas descobertas em durante a aprendizagem, vendo sentido e prática na Matemática.

A princípio, a intenção de trabalhar com os livros didáticos, não foi bem recebida pelos professores, muitos acreditavam perder a liberdade na condução de suas aulas e a falta de segurança de domínio de conteúdos propostos pelos livros, como um conteúdo a ser religiosamente seguido. Porém, com o passar dos anos foi bem aceito e incorporado como material essencial e de grande valia. Com os avanços no currículo da disciplina de Matemática e da própria sociedade brasileira, essa disciplina tão temida precisava responder aos anseios em preparar os alunos para o exercício pleno de cidadão e para o mercado de trabalho (SILVA, 2009).

Consolidando-se como instrumento de orientação pedagógica, os eventos inerentes às possibilidades de formação continuada sempre mereciam posição de destaque nas páginas da REMT, como por exemplo, na edição de número 13 que abordou um encontro de professores no município de Vila Bela da Santíssima Trindade.

As temáticas discutidas neste evento estavam todas 
vinculadas ao fato de que a escola era considerada falha por não levar em conta o contexto social dos alunos, onde estava inserida a unidade escolar da comunidade local. Outro aspecto relevante era o currículo descontextualizado, que segundo os discursos no referido evento deveria atentar-se para as peculiaridades locais, deixando durante todo esse tempo de explorar as múltiplas possibilidades que poderiam surgir dos anseios da comunidade.

A necessidade de voltar à atenção para as reais necessidades do aluno foi o fio condutor da formação de professores na cidade de Vila Bela, o evento enfatizou a importância do acompanhamento das características individuais do aprendizado, a diversificação das atividades, contemplação de elementos da comunidade no planejamento e tornar disto realidade em aula, discussão acerca da avaliação como processo contínuo, orientação para o trabalho com recuperação paralela (MATO GROSSO, 1981).

Os momentos de reflexão da prática cotidiana durante o período de formação continuada surgiram efeito, dando uma nova abordagem ao planejamento. Os exercícios práticos realizados e incentivados geraram os modelos de Planos Diários de ensino, conforme destaca a Figura 1, centrados na realidade do aluno, com elementos que poderiam fazer perfeita correlação com a prática social inerente a vida do aluno.

Figura 1 - Modelo de Plano Diário

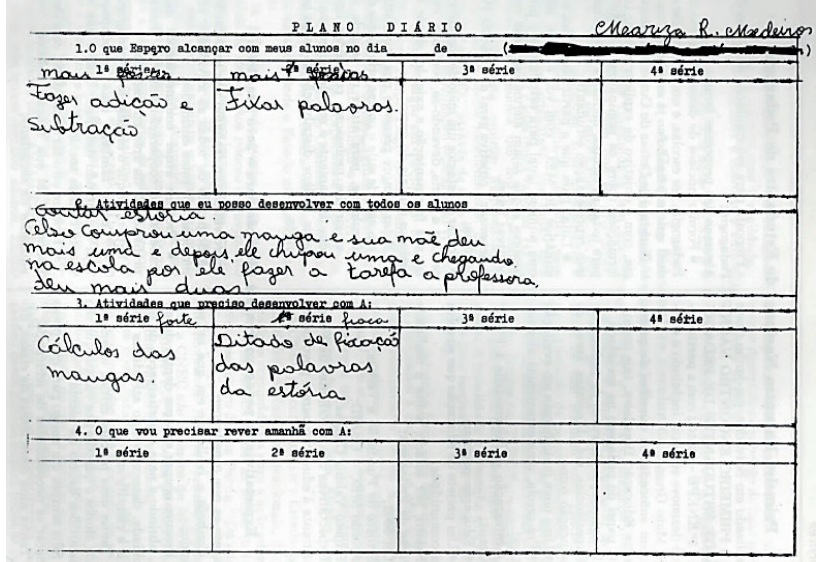

Fonte: REMT (1981).

Muitos exemplos foram sugeridos, dentre os quais destacamos as frutas abundantes no estado, como a manga que poderia ser utilizado como recurso para criar situações problemas com as operações de adição e subtração. Quando se emprega um objeto que seja natural ao ambiente da criança para desenvolver as situações problemas, a sensação de proximidade, de pertencimento e compreensão se amplia, além do respeito à regionalidade e valorização da cultura local.

A formação de professores para ser eficaz deve proporcionar a reflexão, o livre pensamento que entrelaça o pessoal com o profissional, considera-se esta junção indissociável. Nesta perspectiva fica evidente que as ações do professor em sala de aula, advém da identidade profissional construída por meio das experiências e relações estabelecidas no cotidiano da sala de aula. Neste contexto, a formação não se dá apenas pelos cursos de formação, mas nas trocas de conhecimentos significativos e dinâmicos entre os alunos e pares, ou seja, o formador e o formando (NÓVOA, 1992).

A Revista traz como elemento essencial diversas atividades que utilizavam o Tema Gerador uma proposta batizada como "Unidade de Trabalho" onde as disciplinas atuavam de modo multidisciplinar complementando-se. Para as autoras e professoras Ana Dalva Martins Toledo Resende e Elizete Villanova de Senna essas atividades eram centrada em Estudos Sociais (que englobavam as disciplinas de Geografia e História no ensino primário) e enlaçavam as outras disciplinas do currículo como colaborativas que poderiam culminar em excursões, entrevistas, pesquisas, confecção de materiais, teatros, entre tantas outras possibilidades didáticas (MATO GROSSO, 1979).

As proposições feitas pelo Tema Gerador propiciam para a disciplina de Matemática um trabalho integrado e articulado que se conectam as ideias de Piaget (1996) que é preciso ter uma organização inicial do pensamento para a construção de esquemas que advém da adaptação. $\mathrm{O}$ autor afirma que a adaptação é contínua, pois o ser humano está o tempo todo em interações com o meio e com o outro, logo refazendo suas estruturas que assimilam uma nova informação com os conhecimentos prévios que possui e quando compreender do que se trata acomodará um novo conceito, ou seja, a adaptação seria o meio pelo qual se equaciona a assimilação (estrutura mental já possuída) e acomodação (modificação da estrutura para resolver um novo desafio) promovendo alterações cognitivas, possibilitando um novo aprendizado, chegando à equilibração, todas as etapas exigem uma ação, alteração e mudança no estágio inicial das ideias.

A matéria "Unidade de Trabalho" destaca um modelo de planejamento com todas as etapas e orientações para que o grupo de professores envolvidos pudesse constatar se o assunto estava previsto na proposta curricular, se era interessante aos estudantes e oportunizaria ampliar os conhecimentos e desenvolver novas habilidades, possibilitando o engajamento das várias disciplinas. Inclusive dava sugestões de temáticas que poderiam ser exploradas, salientavam ainda que deveria ser um projeto bastante coeso que despertasse a vontade de participação de todos, envolvendo alunos e professores, bem como toda comunidade escolar (MATO GROSSO, 1979).

O exemplo de projeto destacado na Revista, denominado "Vamos conhecer os símbolos da Pátria" com previsão de 15 dias para elaboração e execução das fases planejadas específicas para a disciplina de Matemática enfatizava que os exercícios para interagir com as demais disciplinas seriam explorados os conceitos básicos de escala, perímetro, área, formas geométricas e desenhos geométricos (MATO GROSSO, 1979). 
Figura 2 - Transformações da Bandeira Nacional

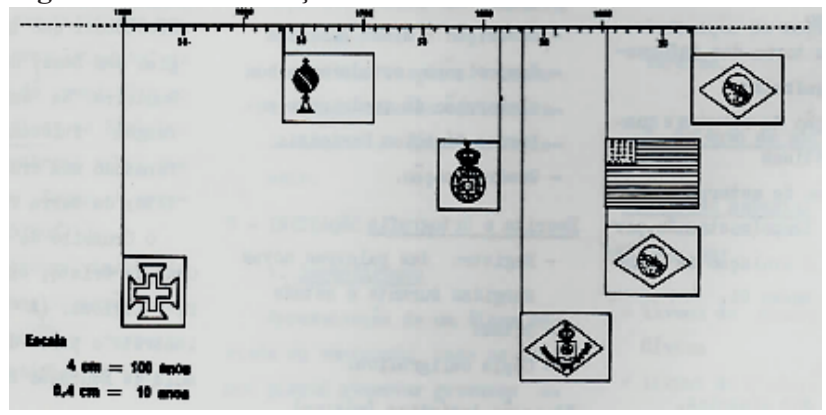

Fonte: REMT (1979).

Possivelmente esses conteúdos seriam contemplados no estudo das formas do Pavilhão Nacional, Armas Nacionais, Selos Nacionais, dentre outros símbolos relacionados com a nação, a proposta era construir a Linha do Tempo destacando as "Transformações da Bandeira Brasileira" com a finalidade de vislumbrar como ocorreram as modificações até chegar ao modelo que é utilizado nos dias atuais.

Outra ideia explícita no projeto "Unidade de Trabalho" figura nas páginas da edição de número 18 com o tema "A Escola" direcionada para estudantes da $2^{\mathrm{a}}$ série do $1^{\circ} \mathrm{Grau}$, com o objetivo de despertar o amor à instituição que estão vinculados, pois somente conhecendo-a bem é que poderiam cuidar melhor e sentir-se como coparticipe da unidade escolar (MATO GROSSO, 1982).

Os objetivos previstos para explorar os conceitos matemáticos estavam relacionados a noções de conjunto, ordem, numeração, adição, sistema monetário e formas geométricas. Desde o soar do sino, a organização da fila para adentrar na sala de aula a sugestão era partir desta situação para trabalhar noções de ordenação, quantidade e correspondências. Como sugestão de conteúdo, todo o espaço físico do estabelecimento de ensino poderia ser utilizado para classificar distintos conjuntos; verificar as janelas, portas e qualquer objeto que possa correlacionar com as formas geométricas, criando assim noções básicas de associações; proceder cálculos, visualizar a presença de números e praticar a Matemática. Todo o projeto foi pensado e direcionado para a realidade cotidiana da criança e suas vivências na escola, considerando que é o local onde passa a maior parte do tempo e constrói suas relações sociais e tem a oportunidade de crescer como indivíduo (MATO GROSSO, 1982).

A cultura escolar é o que acontece no interior de cada instituição de ensino, são regras previamente definidas que destacam os direitos e deveres, conhecimentos que devem ser "inculcados" nas crianças e transmitidos desde a infância. São relações estabelecidas entre os pares que convivem no mesmo ambiente convivendo ou apenas observando comportamentos que ao longo dos anos interferem no andamento do processo escolar (política, religião, entre outros), sendo ainda possível delimitar as práticas cotidianas que permeiam o fazer escolar (JULIA, 2001).

"Quando a escola foi à festa e a festa à escola" é outra opção que agrega o exercício do trabalho multidisciplinar. Nesta matéria percebe-se a importância de valorizar as atividades cotidianas inerentes ao ambiente escolar, estimulando o professor buscar as tradições locais e exaltálas em conjunto com a comunidade escolar no interior da instituição, com o intuito de uma participação efetiva e sentirse como atores principais que podem e devem participar promovendo a cultura com as mais variadas expressões da arte, como a dança, música e até mesmo o artesanato local. (MATO GROSSO, 1982).

A parte do artesanato também se alia aos conteúdos de Matemática, compreende-se que para ornamentar a escola é preciso empregar cálculos e usar variadas noções geométricas. O planejamento de como usar os materiais para decoração e ter menor quantidade de sobras contribui sobremaneira com o uso de moldes para recortar bandeirolas, dobraduras que trabalha o raciocínio espacial e estimula o raciocínio lógico (MATO GROSSO, 1982).

A compreensão dos conceitos matemáticos destacado na Revista, o que, como e para que ensinar, tem grande relevância para as crianças no sentido de atribuir significados aos conteúdos, que muitas vezes são descontextualizados e sem significado nenhum. Neste cenário, o estímulo constante do professor em oferecer trabalhos diferenciados instiga a curiosidade do aluno e o interesse em participar das atividades propostas em sala de aula.

A intenção é que se tornem sujeitos ativos no processo de ensino e aprendizagem durante de aulas de Matemática, oportunizando trocas de experiências com o professor e os colegas favorecendo o aprendizado e colaborando ainda com a construção do perfil de estudante mais participativo, questionador que prefere discutir e compreender onde os conteúdos aplicados poderão ser utilizados dentro e fora da sala de aula (GRANDO; GONÇALVES, 2019).

No período de circulação da Revista Educação em Mato Grosso, a teoria de Piaget estava sendo difundida em várias partes do mundo, inclusive no Brasil. Segundo o autor, para aprender Matemática, o aluno precisa pensar sobre o que aprende e este pensar está ancorado nas relações que estabelece com sua prática social. Entretanto, o professor deve diversificar as atividades e oferecer desafios que leve o próprio estudante a novas descobertas para que possa compreender os conceitos estudados. Ainda nos chama a atenção em relação ao processo de aprendizagem que deve ser desafiadora, significativa e rejeita todo e qualquer exercício que exige repetição e decoreba. Piaget (1978) ainda assevera que a aprendizagem é tendenciada a surgir quando se interliga as informações que o indivíduo tem internalizadas com as novas que lhes são apresentadas.

Em consonância ao processo de ensinar e aprender, Freire (2002) afirma que a tarefa do docente não é meramente repassar informações e conteúdo, esperando que o aluno reproduza fielmente o que fora explicado durante as aulas e nas avaliações. Cabe ao professor conduzir as aulas de modo 
a ensiná-los a pensar, despertar a capacidade de interiorizar e reproduzir com seu próprio entendimento, os tópicos de aula em conjunto com o emaranhado de situações que a criança já traz consigo, ou seja, valorizar os conhecimentos prévios para que reconstrua aquilo que lhe fora ensinado.

"Integração Social" foi uma matéria que preza pelas minúcias ao apresentar uma proposta de projeto que envolvesse todas as disciplinas de modo prático detendo-se nas situações cotidianas e na formação cidadã. No entanto, centrar-se nas habilidades e competências que gostariam que fossem desenvolvidas torna-se uma missão essencial ao detalhar a escrita multidisciplinar direcionando-a para a prática. Realizar a sondagem inicial dos conhecimentos que os alunos já possuem sobre o tema escolhido, situa bem o ponto de partida e de interesse da classe (MATO GROSSO, 1978).

A unidade de estudo "Transporte" direcionada para a $4^{\text {a }}$ série do ensino primário, mais uma vez contempla a Matemática e destaca os conhecimentos de Unidades de Medida de Comprimento e Conhecimentos Geométricos. As linhas que o transporte público faz, os trajetos que eram possíveis de realizar ligando dois pontos, o desenho destas situações, a extensão dos caminhos e o tempo gasto para tal, além dos recursos financeiros que deveriam ser empregados para realizar tais viagens, poderiam ser assunto de discussão durante as aulas, complementando a pesquisa e estudos que as demais disciplinas estavam concomitantemente desenvolvendo, podendo inclusive culminar na construção de maquetes para expor o trabalho de todas as áreas de conhecimento (MATO GROSSO, 1978).

Similarmente na REMT de número 2 do ano de 1979, aventou-se um projeto trazendo como eixo norteador uma visita de campo em uma cooperativa de lacticínios. O modelo de planejamento destinava-se aos conteúdos pertencentes à $7^{\mathrm{a}}$ série do $1^{\circ} \mathrm{Grau}$, todavia como todas as atividades eram sugestões, cabia aos professores de outras séries, aproveitar a temática ou ainda elaborar um plano coletivo para a unidade escolar, necessitava apenas adaptá-lo. Como exemplo, a matéria destaca que para o ensino primário seria possível contextualizar a Matemática de várias formas, como as situações problemas envolvendo a entrega de leite pelo produtor, a compra de leite como produto final no mercado, as unidades de medidas com reconhecimento de litro, múltiplos e submúltiplos, receitas utilizando o leite dentre outras. Como o impresso permanentemente reforça a força de vontade para explorar os conteúdos e fazer acontecer, isso dependeria do engajamento da equipe em cada unidade escolar (MATO GROSSO, 1979).

Ainda sobre a Matemática interligada as demais disciplinas, as gincanas contavam com provas que envolviam os conhecimentos matemáticos como montar quebracabeças, resolver cálculos (com ou sem auxílio de papel e lápis), responder rapidamente a tabuada, recortar figuras geométricas, dentre outras possibilidades, para realizar uma competição estudantil saudável em clima estudantil, aferindo as habilidades e gerando diversão e convívio social (MATO GROSSO, 1978).

$\mathrm{Na}$ primeira edição é engrandecido o "currículo por atividade" que era caracterizado como a aprendizagem com situações concretas exemplificando com o projeto "A casa" que nesta sugestão tinha como disciplina principal a Geografia. Entretanto, a matéria entrelaçava as demais disciplinas, prevista como possibilidade de aplicação em todas as séries do primário. A Matemática se fazia presente no uso de materiais que contemplavam noções de Geometria, como a régua para fazer o esboço da casa, lançando mão de formas geométricas; medir uma casa de tamanho real para entendimento das unidades de medidas; realizar pesquisa de preços de materiais de construção em diferentes lojas, trabalhando o sistema financeiro; quantidade de tijolos empregados na construção da parede ou a quantificação de telhas; introdução às noções de área e perímetro; dentre outras perspectivas que o tema oferece (MATO GROSSO, 1978).

No periódico, ainda na matéria "A casa" existe uma referência à sistemática sugerida e muito pertinente à teoria de Piaget (1977) a condução do projeto tinha relação com as ideias defendidas pelo teórico, quando afirma que a cada nova aprendizagem é gerada um novo equilíbrio em função das estruturas anteriores dos conhecimentos prévios, a assimilação do mundo à sua volta e nova organização por meio da acomodação (PIAGET, 1977). Simultaneamente o professor precisa garantir que o aluno tenha chances de perceber como um conteúdo é ligado a outro de forma sequencial e ao se apropriar desses novos conhecimentos estabelece conexões com o conhecimento adquirido anteriormente (MATO GROSSO, 1978).

Figura 3 - Assimilação, acomodação, adaptação e equilibração na visão de Piaget

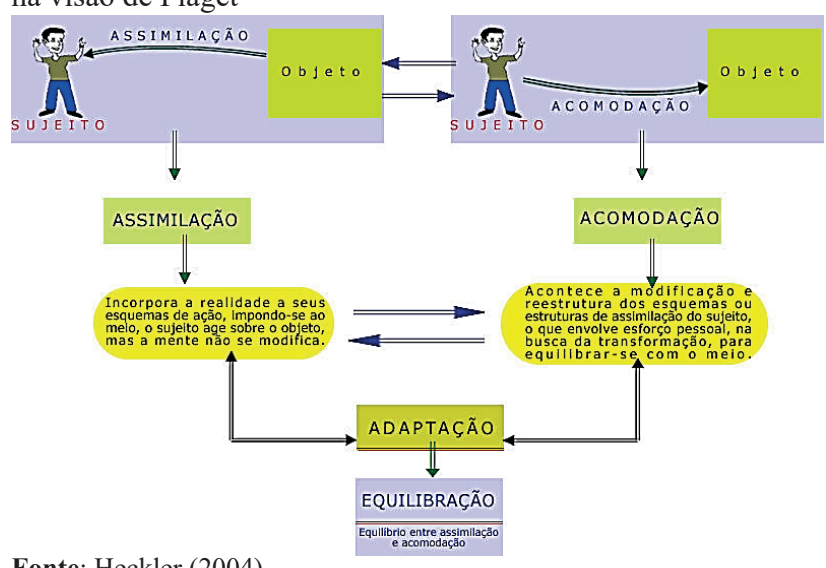

Fonte: Heckler (2004).

Outro destaque que contribui para o ensino de Matemática destacado pela Revista é Método Montessori. O tema é abordado por Idelma Pantarotto e os materiais divulgados como montessoriano, segundo a autora advém das experiências de Maria Montessori, formada em medicina realizou estudos com crianças deficientes que também apresentavam dificuldades 
de aprendizagem. Os recursos utilizados essencialmente sensoriais eram muito atrativos pelas cores e tinha como finalidade o uso didático, destacando que a aprendizagem poderia ser vislumbrada com o uso dos objetos por meio de brincadeiras dirigidas. Segundo Montessori (1965), quando a criança explora o material, posteriormente abstrai conceitos sobre ele usando o raciocínio lógico matemático, como os agrupamentos e comparações com formas geométricas que são incentivados especificamente para o ensino de conteúdos matemáticos (MATO GROSSO, 1979).

O estudo do tema "Higiene e Saúde" demostrando a articulação entre as disciplinas poderia ser uma proposta ampla para as mais variadas faixas etárias de alunos envolvendo hábitos de higiene, prevenção de doenças, importância de vacinas, e outros onde se propunha o uso de cartazes geradores da temática com a exploração de textos com a finalidade de conscientizar a comunidade escolar. Neste tema a Matemática também tem destaque para fazer a interpretação dos dados numéricos presentes nos materiais disponibilizados para leitura e compreensão do papel sobre a importância da quantificação, sequenciação e tipos de representações numéricas que ocupam lugar na vida das pessoas (MATO GROSSO, 1980).

O uso de materiais reutilizáveis para a construção de materiais concretos está enfatizada na matéria denominada "Material de Ensino-Aprendizagem" com grandes vantagens apresentadas pelos autores que destacam a elaboração com a participação do próprio aluno, utilizando recursos com baixo custo e reaproveitamento, que os mesmos poderiam coletar e trazer para a escola. A metodologia traria benefícios, quando o estudante participa da construção tem maior interesse e favorece melhor assimilação dos conteúdos (MATO GROSSO, 1980).

Figura 4 - Tabuleiro do Jogo "Corrida"

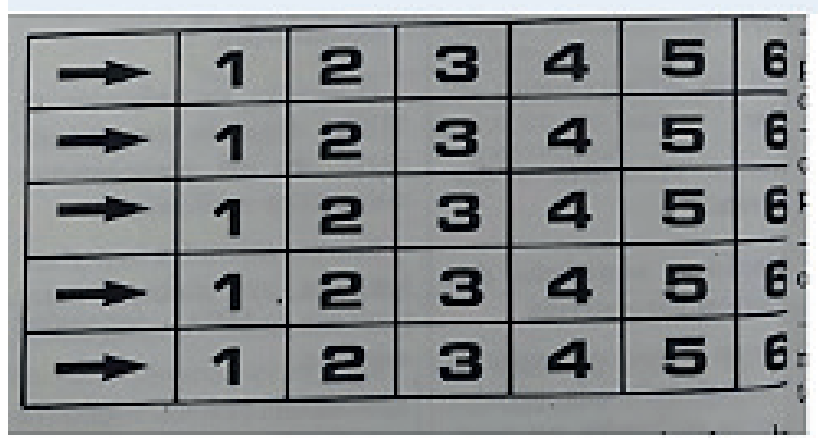

Fonte: REMT (1980).

Para a disciplina de Matemática a sugestão é o jogo designado como "Corrida" que serve para fixação das quatro operações básicas (adição, subtração, multiplicação e divisão), um tabuleiro que aponta a saída e chegada com números dispostos em ordem crescente como um percurso a ser vencido. Cada jogador deve ter uma tampinha distinta com números para identificar e marcar sua posição na trilha do jogo em sua raia, para ter direito ao avanço, o jogador precisa sortear uma ficha que contenha um cálculo para ser resolvido e estar correto, podendo ter níveis diferentes de dificuldade para cada etapa do circuito (MATO GROSSO, 1980).

No tema "Promoções Culturais na Escola de $1^{\circ}$ e $2^{\circ}$ Graus" a manifestação cultural regional deve ser preservada e divulgada nas atividades realizadas no ambiente escolar pelos estudantes e também pela comunidade. Nesta proposta é que a equipe escolar faça um diagnóstico para conhecer os interesses locais e valorize as possibilidades de sugestões. Para explorar os conteúdos de Matemática, o professor poderá usar unidades de medidas e introduzir noções de horas e ainda aproveitar para discorrer acerca das unidades de tempo em anos, décadas, etc.; realizar agrupamentos de alunos em pares e grupos para explorar as lendas, jogos, contos e outras variantes de acordo com o planejamento realizado apropriadamente para aquela determinada escola (MATO GROSSO, 1982).

No conteúdo da matéria "Operacionalização do currículo por atividades na escola de $1^{\circ}$ Grau” há evidências de grande preocupação em melhorar a educação em Mato Grosso, existem afirmativas no sentido de discussões efervescentes de várias classes sentem a necessidade de distanciar da teoria e vislumbrar a aplicabilidade que está prevista na Lei de Diretrizes e Bases (5692/71). Apostando em alternativas para que o ensino seja mais atrativo e significativo, a temática se respalda na teoria piagetiana para compreender as fases desenvolvimentistas dos estudantes. Dentre outros tópicos pertinentes, a matéria traz como exemplo o trabalho desenvolvido na Escola Sagrado Coração de Jesus, sediada na capital, para a $2^{\mathrm{a}}$ série do $1^{\mathrm{o}}$ Grau atividades centradas nas "Plantas" onde propõe a articulação envolvendo todas as disciplinas (MATO GROSSO, 1983).

Neste projeto fica evidenciado a Matemática Moderna, com a presença da teoria de conjuntos, e atividades com as operações matemáticas envolvendo adição e subtração, distinção entre unidade e dezena e multiplicação como operação derivada da adição com agrupamentos. As atividades previstas sugerem o uso de sementes, flores, folhas, frutos e barbantes para delimitar os conjuntos, objetos que os alunos podem trazer de casa ou coletar com o professor no pátio ou entorno da escola, dentro do espaço organizado com barbante. Os alunos seriam estimulados a construir um conjunto unitário de semente, um conjunto com dez elementos composto por folhas e utilizar as partes das plantas para concretamente efetuar cálculos simples por meio de agrupamentos e contagens para posteriores registros organizados na lousa e/ ou caderno. De acordo com a REMT estratégias como estas podem favorecer a educação a "tornar concreto e real para que venha ser assertiva” (MATO GROSSO, 1983).

$\mathrm{Na}$ abordagem da disciplina de Física feita pelo Professor Jorge Soares de Almeida que atuava na Escola Estadual Presidente Médici é proposta a construção de lunetas simples usando materiais acessíveis, chamando a atenção para o trabalho interdisciplinar com a disciplina de Matemática. 
A elaboração do material requer domínio de Unidades do Sistema Métrico e apresenta um esquema com desenhos, orientando como deve ser a montagem das peças, porém, a atividade é direcionada para o $2^{\circ}$ Grau. No entanto, os alunos de $1^{\circ}$ Grau poderiam conhecer e manusear os materiais de forma assistida pelo professor e monitorados pelos próprios alunos que construíram em função do assunto estar em alta, com a passagem do Cometa Halley que se torna um fenômeno mundial, famoso por ser visível de tempos em tempos no planeta Terra (MATO GROSSO, 1986).

Figura 5 - Faça a sua própria luneta

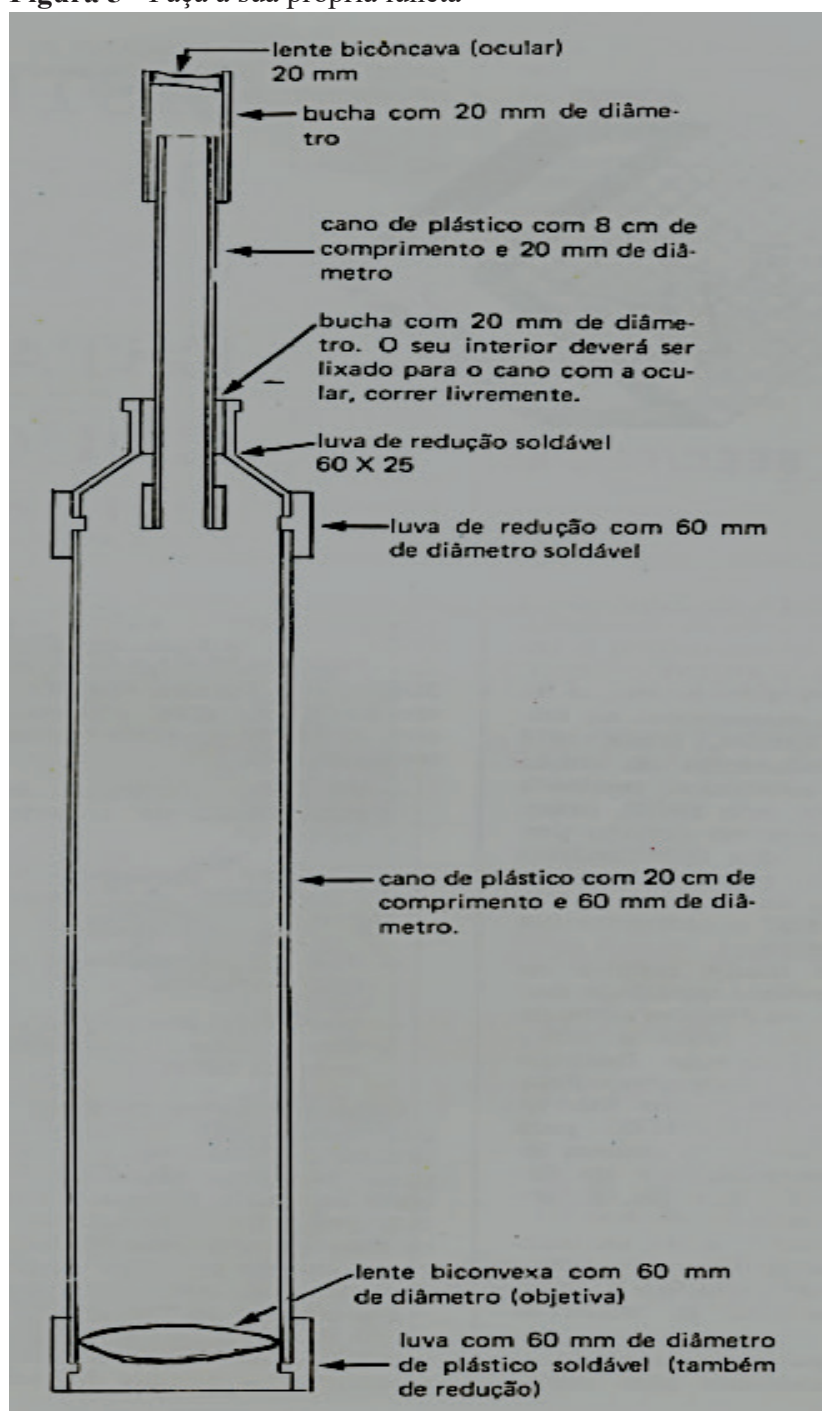

Fonte: Mato Grosso, n.31 (1986).

Outro aspecto relevante e salutar são as indicações de bibliografias para o professor, dentre elas, a obra de Luiz Alberto S. Brasil de 1977, denominada "Aplicação da Teoria de Piaget ao Ensino da Matemática" contém um resumo que que contextualiza as aplicações feitas através dos estudos de Piaget onde valoriza o agrupamento para treinar o pensamento hipotético, bem como a expressão corporal. Traz informações da Educação Infantil ao Ensino Médio. Na época tido como uma literatura destinada aos professores do pré-primário ao $2^{\circ}$ Grau (MATO GROSSO, 1981).
Outra obra que tem recomendação inerente a Matemática denominada de "Planos Instrucionais para Ensino por Objetivos" do Ministério da Educação com organização de Consuelo de Menezes Garcia e outros autores no ano de 1976. A obra contempla os planos de trabalho como sugestão às equipes que estavam elaborando as novas propostas curriculares, com a tarefa de analisar os domínios cognitivo, afetivo e psicomotor (MATO GROSSO, 1979).

Como exposto anteriormente, a SEDUC fornece todo o amparo de como deveria ser pensado e executado o "Dia D" da educação que culminou na reunião com a participação de representantes no plenário em nível estadual. As indagações motivadoras giravam em torno do modelo de escola existente e sonhavam com um modelo ideal que ultrapassassem os muros da unidade escolar. Como um objetivo a ser alcançado, chamaram todos à responsabilidade no sentido de repensar e ressignificar tudo que estava relacionado a uma educação de qualidade e que realmente fizesse a diferença para toda comunidade escolar (MATO GROSSO, 1982).

A REMT retratou neste número especial, como tudo transcorreu nos fóruns municipais demonstrando os resultados sistematizados para que se tornassem públicas as aspirações que foram relatadas dentro de cada unidade escolar do estado de Mato Grosso (MATO GROSSO, 1982).

As sugestões publicadas na Revista para a disciplina de Matemática foram descritas no relatório estadual acerca das discussões dos 58 municípios participantes. Articulados em 18 polos regionais redigiram as sugestões que foram elencadas destacando que os tópicos referentes à teoria dos conjuntos da Matemática Moderna fossem minimizados por conta da exaustão, sugerindo que fossem sintetizados; em relação ao conteúdo de Estatística os apontamentos enfatizam que era necessário adequar as aulas com os interesses de cada curso técnico, tornando os conteúdos aplicáveis na prática; para o ensino primário a solicitação é que o ensino fosse direcionado para as quatro operações básicas e a resolução de problemas enfatizando que o raciocínio lógico seja desenvolvido ao máximo pelo professor em sala de aula e o retorno como obrigatoriedade da tabuada decorada (MATO GROSSO, 1982).

Como forma de valorizar a disciplina de Matemática a solicitação refere-se a ampliação da carga horária, justificamna como insuficiente e sugere que o professor tenha acréscimo na hora atividade com a finalidade para melhor planejar as aulas. Cinquenta $(50 \%)$ dos municípios entenderam que as solicitações eram prioridades e consideradas como uma necessidade emergencial (MATO GROSSO, 1982).

Neste sentido Chervel (1990, p.180) nos chama a atenção a finalidade dos conteúdos e como são efetivamente ensinados, como são aprendidos, a observância destes se torna um parâmetro para verificar como se dá a cultura produzida na e pela escola, "os conteúdos de ensino são impostos como tais à escola pela sociedade que a rodeia e pela cultura na qual ela se banha". 
Nas pautas que destacam o ensino de Matemática é perceptível as ambições para que se torne uma disciplina acessível, contextualizada e aplicável por meio de atividades práticas com uso de materiais concretos para que adquira uma aprendizagem real, significativa e mais próxima da vida do aluno. Fica evidente que a concepção construtivista mesmo de forma implícita se faz presente. A teoria enfatiza que a relação do indivíduo com o meio gera aprendizagem.

Nesta perspectiva, o aluno é a razão de todos os esforços do professor que tem o papel de mediar sua aprendizagem, oportunizando atividades desafiadoras onde o estudante possa construir seu próprio saber por meio de descobertas, tendo como aliado os conhecimentos prévios que traz consigo e a cada novo conceito reconstrói ampliando suas ideias (PIAGET, 1975).

\section{Conclusão}

Analisar fontes documentais que retratam a história da educação matemática em Mato Grosso possibilitou-nos reconhecer a Revista Educação em Mato Grosso como um impresso rico, cheio de detalhes de altíssima qualidade em suas abordagens, configurando-se como um instrumento de orientação e suporte pedagógico para a formação de professores, tornando-se uma grande aliada ao trabalho disseminado nas escolas públicas primárias da rede estadual de ensino. Além de vasta informação, a Revista oferece por meio das matérias divulgadas a disciplina de Matemática de forma dinâmica, significativa e contextualizada inerentes aos interesses reais dos alunos. Outro aspecto relevante são as experiências bem-sucedidas nas diferentes áreas de conhecimento partilhadas pelas escolas.

Diante deste cenário positivo, a Matemática na Revista é tratada e estimulada a ser trabalhada como algo acessível e possível de ser contextualizada por meio das vivências, abarcando os diversos interesses dos alunos. Traz como recurso o uso de materiais manipuláveis e teorias que contribuam para que os professores pudessem ter noções de como aprimorar o processo de aprendizagem aliada às questões psicológicas e a legislação vigente para que as escolas pudessem manterse atualizadas e desta forma desenvolver suas atividades de forma legítima. A Revista Educação em Mato Grosso marcou o cenário da educação mato-grossense com propostas reais e possíveis de serem executadas, necessitando de boa vontade política, investimento na formação de professores, articulação, criatividade e compromisso da equipe escolar.

\section{Referências}

CHARTIER, R. A história cultural: entre práticas e representações. Lisboa: DIFEL, 1990.

CHERVEL, A. História das disciplinas escolares: reflexões sobre um campo de pesquisa. Teoria Educ., n.2, p.177-229, 1990.

FREIRE, P. Pedagogia da Autonomia: saberes necessários à prática educativa. São Paulo: Paz e Terra, 2002.

GRANDO, R.C.; GONÇALVES, A. Processos formativos de professores no movimento das feiras catarinenses de matemática: estudo de caso. Rev. Matem. Ensino Cultura, n.30 2019, p.41-55. doi: 10.37084/REMATEC.1980-3141.2019.n30.p\%p.id175

HECKLER, V. Uso de simuladores e imagens como ferramentas auxiliares no ensino/aprendizagem de ótica. Porto Alegre: UFRGS, 2004.

JULIA, D. A cultura escolar como objeto histórico. Rev. Bras. Hist. Educ., n.1, p.9-44, 2001.

MATO GROSSO. Secretaria Estadual de Educação e Cultura. Revista Educação em Mato Grosso. Cuiabá, n. 1, 1978.

MATO GROSSO. Secretaria Estadual de Educação e Cultura. Revista Educação em Mato Grosso. Cuiabá, n. 2,1978.

MATO GROSSO. Secretaria Estadual de Educação e Cultura. Revista Educação em Mato Grosso. Cuiabá, n. 4, 1978.

MATO GROSSO. Secretaria Estadual de Educação e Cultura. Revista Educação em Mato Grosso. Cuiabá, n. 2, 1979.

MATO GROSSO. Secretaria Estadual de Educação e Cultura. Revista Educação em Mato Grosso. Cuiabá, n. 3, 1979.

MATO GROSSO. Secretaria Estadual de Educação e Cultura. Revista Educação em Mato Grosso. Cuiabá, n. 4, 1979.

MATO GROSSO. Secretaria Estadual de Educação e Cultura. Revista Educação em Mato Grosso. Cuiabá, n. 1, 1980.

MATO GROSSO. Secretaria Estadual de Educação e Cultura. Revista Educação em Mato Grosso. Cuiabá, n. 2, 1980.

MATO GROSSO. Secretaria Estadual de Educação e Cultura. Revista Educação em Mato Grosso. Cuiabá, n. 13, 1981.

MATO GROSSO. Secretaria Estadual de Educação e Cultura. Revista Educação em Mato Grosso. Cuiabá, n. 14, 1981.

MATO GROSSO. Secretaria Estadual de Educação e Cultura. Revista Educação em Mato Grosso. Cuiabá, n. 15, 1982.

MATO GROSSO. Secretaria Estadual de Educação e Cultura. Revista Educação em Mato Grosso. Cuiabá, n. 18, 1982.

MATO GROSSO. Secretaria Estadual de Educação e Cultura. Revista Educação em Mato Grosso. Cuiabá, n. 22, 1982.

MATO GROSSO. Secretaria Estadual de Educação e Cultura. Revista Educação em Mato Grosso. Cuiabá, n. especial, 1982.

MATO GROSSO. Secretaria Estadual de Educação e Cultura. Revista Educação em Mato Grosso. Cuiabá, n. 20, 1983.

MATO GROSSO. Secretaria Estadual de Educação e Cultura. Revista Educação em Mato Grosso. Cuiabá, n. 31, 1983.

MONTESSORI, M. Pedagogia cientifica. Rio de Janeiro: Flamboyant, 1965.

NÓVOA, A. Formação de professores e profissão docente. In: NÓVOA, A. Os professores e a sua formação. Lisboa: Dom Quixote, 1992.

PIAGET, J. A equilibração das estruturas cognitivas. Rio de Janeiro: Zahar, 1975.

PIAGET, J. A formação do símbolo na criança. Rio de Janeiro: Zahar, 1978.

PIAGET, J. Biologia e conhecimento. Petrópolis: Vozes, 1996.

PIAGET, J. Psicologia da inteligência. Rio de Janeiro: Zahar, 1977.

SILVA, J.R. Matemática no Ensino Primário: duas paisagens, uma história, muitas interrogações. São Paulo: UNESP, 2009. 